\title{
Back pain improvement after decompression without fusion or stabilization in patients with lumbar spinal stenosis and clinically significant preoperative back pain
}

\author{
Charles H. Crawford III, MD,, Steven D. Glassman, MD, ${ }^{1,2}$ Praveen V. Mummaneni, MD, ${ }^{3}$ \\ John J. Knightly, MD, ${ }^{4}$ and Anthony L. Asher, MD ${ }^{5}$ \\ ${ }^{1}$ Norton Leatherman Spine Center, Louisville; 2University of Louisville, Kentucky; ${ }^{3}$ Department of Neurological Surgery, \\ University of California, San Francisco, California; ${ }^{4}$ Atlantic NeuroSurgical Specialists, Morristown, New Jersey; and ${ }^{5}$ Carolina \\ Neurosurgery \& Spine, Charlotte, North Carolina
}

\begin{abstract}
OBJECTIVE The relief of leg symptoms by surgical decompression for lumbar stenosis is well supported by the literature. Less is known about the effect on back pain. Some surgeons believe that the relief of back pain should not be an expected outcome of decompression and that substantial back pain may be a contraindication to decompression only; therefore, stabilization may be recommended for patients with substantial preoperative back pain even in the absence of well-accepted indications for stabilization such as spondylolisthesis, scoliosis, or sagittal malalignment. The purpose of this study is to determine if patients with lumbar stenosis and substantial back pain-in the absence of spondylolisthesis, scoliosis, or sagittal malalignment—can obtain significant improvement after decompression without fusion or stabilization.
\end{abstract}

METHODS Analysis of the National Neurosurgery Quality and Outcomes Database (N²QD) identified 726 patients with lumbar stenosis (without spondylolisthesis or scoliosis) and a baseline back pain score $\geq 5$ of 10 who underwent surgical decompression only. No patient was reported to have significant spondylolisthesis, scoliosis, or sagittal malalignment. Standard demographic and surgical variables were collected, as well as patient outcomes including back and leg pain scores, Oswestry Disability Index (ODI), and EuroQoL 5D (EQ-5D) at baseline and 3 and 12 months postoperatively.

RESULTS The mean age of the cohort was 65.6 years, and $407(56 \%)$ patients were male. The mean body mass index was $30.2 \mathrm{~kg} / \mathrm{m}^{2}$, and $40 \%$ of patients had 2-level decompression, $29 \%$ had 3-level decompression, $24 \%$ had 1 -level decompression, and $6 \%$ had 4 -level decompression. The mean estimated blood loss was $130 \mathrm{ml}$. The mean operative time was 100.85 minutes. The vast majority of discharges (88\%) were routine home discharges. At 3 and 12 months postoperatively, there were significant improvements from baseline for back pain (7.62 to 3.19 to 3.66 ), leg pain (7.23 to 2.85 to 3.07), EQ-5D (0.55 to 0.76 to 0.75$)$, and ODI (49.11 to 27.20 to 26.38$)$.

CONCLUSIONS Through the 1st postoperative year, patients with lumbar stenosis-without spondylolisthesis, scoliosis, or sagittal malalignment-and clinically significant back pain improved after decompression-only surgery.

http://thejns.org/doi/abs/10.3171/2016.3.SPINE151468

KEY WORDS lumbar spinal stenosis; back pain; surgery; decompression without fusion; registry; outcomes

$\mathrm{S}$ URGICAL treatment of lumbar stenosis is well supported by current medical evidence..$^{1,10-12,16,19,21}$ Controversy exists regarding the role of supplemental stabilization or fusion in the absence of gross instability or deformity. ${ }^{3,6,15,17-18,20}$ Previous authors have noted the conventional theory that patients with significant back pain symptoms may not be adequately improved with decompression-only surgery. ${ }^{3,15}$ Surgeons may use this the- ory to justify a fusion or other stabilization procedure, in addition to decompression of symptomatic spinal stenosis when a patient complains of substantial preoperative back pain. For example, the inclusion criteria for a recent FDA investigational device exemption study that evaluated an interspinous process device versus instrumented fusion included patients with lumbar spinal stenosis and a back pain score greater than 5 of $10,5,6,20$ The implication is that

ABBREVIATIONS BP = back pain; EQ-5D = EuroQoL 5D; LP = leg pain; MCID = minimum clinically important difference; N2QD = National Neurosurgery Quality and Outcomes Database; ODI = Oswestry disability index.

SUBMITTED December 14, 2015. ACCEPTED March 11, 2016.

INCLUDE WHEN CITING Published online June 10, 2016; DOI: 10.3171/2016.3.SPINE151468. 
patients with substantial preoperative back pain are often recommended for a stabilization procedure or fusion in addition to decompression.

In a recently published guideline update regarding the surgical treatment of spinal stenosis, Resnick et al. ${ }^{18}$ stated that prospective patient registries may identify a specific subgroup of patients with routine lumbar stenosis who may benefit from lumbar fusion in addition to decompression. This expectation may or may not be realistic. Registries are advantageous in that they reflect existing treatment in standard clinical practice. However, they often lack the granularity necessary to answer specific questions. ${ }^{9,13}$ Our study attempts to explore the question of whether patients with substantial preoperative back pain may improve with decompression-only surgery, or whether they necessarily require a more extensive and expensive surgical approach.

\section{Methods}

The National Neurosurgery Quality and Outcomes Database $\left(\mathrm{N}^{2} \mathrm{QOD}\right)$ is a prospective, multicenter, quality assurance program with a substantial infrastructure to optimize data integrity and validity. The structure and methodology of the $\mathrm{N}^{2} \mathrm{QOD}$ registry have been reported elsewhere.,12-14 The first 6 patients scheduled for lumbar surgery for a given week are identified and asked to complete questionnaires during their visit, by mail, or by telephone. Each enrollment week has a different start date that is standard for all sites. This sampling method prevents a disproportionate volume of enrollment from one surgeon's schedule at each site. There are currently 1128 surgeons participating across 79 sites in the United States.

Patient enrollment is based on well-defined diagnostic criteria, as assessed by the treating surgeon, and includes disc herniation, recurrent disc herniation, spondylolisthesis, stenosis, adjacent-segment disease, and mechanical disc collapse. Patient demographics, surgical parameters, and complications are collected by on-site data extractors. Follow-up questionnaires, which include questions on medication use, return to work, and patient-reported outcomes, are collected at 3 months $( \pm 2$ weeks) and 12 months ( \pm 4 weeks) after surgery. No radiographic data are collected.

The database was queried in October 2014 and identified 845 patients with a diagnosis of lumbar stenosis and a baseline back pain score $\geq 5$ of 10 who underwent a decompression procedure without fusion. As part of the criteria for enrollment, all patients with a diagnosis of stenosis are primary cases and the revisions were excluded. A threshold back pain score of greater than or equal to 5 was chosen to represent the median on the 1 to 10 numeric rating scale. In the database, 294 patients with a primary diagnosis of stenosis had a back pain score $<5$ and were excluded. None of the included patients were reported to have significant spondylolisthesis, scoliosis, or sagittal malalignment.

Standard demographic and surgical variables were collected. Patient-reported outcomes, including back and leg pain numeric rating scores (0-10), Oswestry disability (version 2.1), ${ }^{8}$ and EuroQoL 5D (EQ-5D), ${ }^{7}$ were collected at baseline and 3 and 12 months postoperatively. As part of the registry data, information on the patient's predominant complaint was available. The cohort was then classified into 3 groups: back pain-predominant (BP-Dominant) group, leg pain-predominant (LP-Dominant) group, and back pain equal to leg pain $(\mathrm{BP}=\mathrm{LP})$ group. The proportion of patients who achieved the minimum clinically important difference (MCID) ${ }^{4}$ within each subgroup was also determined.

Statistical analysis was carried out using IBM SPSS software (version 21.0). To account for multiple concurrent analyses, significance was set at $\mathrm{p}<0.01$ for all comparisons. One-way ANOVA was used to determine any significant differences between the continuous demographic variables and compare the preoperative and postoperative health-related quality-of-life scores among the 3 groups, and the Fisher's exact test was used to compare categorical variables among the 3 groups.

\section{Results}

Of the 845 cases eligible for follow-up, $726(86 \%)$ had 12-month data available. The mean age of the cohort was 65.6 years, and 407 (56\%) patients were male. The mean body mass index was $30.2 \mathrm{~kg} / \mathrm{m}^{2}$ (range $13.1-53.1 \mathrm{~kg} / \mathrm{m}^{2}$ ). Smoking status was as follows: $50 \%$ (326) of patients reported being nonsmokers, $30 \%$ (221) were former smokers, and $18 \%$ (128) were current smokers. Of these 726 patients, 294 (40\%) underwent 2-level decompression, 208 (29\%) underwent 3-level decompression, 177 (24\%) underwent 1-level decompression, and 47 (6\%) underwent 4-level decompression. The mean estimated blood loss was $130 \mathrm{ml}$ (range 0-2400 ml). The mean operative time was 100.85 minutes (range 21-387 minutes). The vast majority of discharges $(88 \%)$ were routine home discharges (Table 1).

At 3 and 12 months postoperatively, there were significant improvements from baseline for back pain (7.62 to 3.19 to 3.66 ; $\mathrm{p}<0.001$ ), leg pain (7.23 to 2.85 to 3.07 ; $\mathrm{p}<$ $0.001)$, EQ-5D (0.55 to 0.76 to $0.75 ; \mathrm{p}<0.001)$, and ODI (49.11 to 27.20 to 26.38 ; $\mathrm{p}<0.001)$. Mean back pain slightly increased from the 3-month to the 12-month follow-up $(\mathrm{p}=0.002)$ (Table 2).

When patients were grouped by the number of levels decompressed, there were no significant differences between groups for baseline back pain, change in back pain at 3 months, or change in back pain at 12 months. Baseline leg pain was lower in the patients who underwent decompression over 4 levels. For ODI and EQ-5D, there were no significant differences between groups for baseline scores or postoperative change in score (Table 3 ).

When patients were stratified by the dominant symptom, all groups reported significant postoperative improvement in back pain, leg pain, EQ-5D, and ODI. Ultimately, at the 1-year postoperative follow-up, the LP-Dominant group had less back pain and better EQ5D and ODI scores than the BP-Dominant and BP $=\mathrm{LP}$ groups (Table 4).

Similarly, fewer patients in the BP-Dominant group reached MCID ${ }^{4}$ for leg pain improvement at 1 year (Table 5). However, the majority of patients in all groups reached $\mathrm{MCID}^{4}$ at 1 year for ODI improvement, leg pain improvement, and back pain improvement (Table 5). 
TABLE 1. Patient demographic and surgical data

\begin{tabular}{|c|c|}
\hline Variable & Value* $^{*}$ \\
\hline No. of patients & 726 \\
\hline Mean age, yrs & 65.63 \\
\hline Male sex & 407 \\
\hline Mean BMI, kg/m² & 30.2 \\
\hline \multicolumn{2}{|l|}{ Smoking status } \\
\hline Current every day smoker & 117 \\
\hline Current some days smoker & 11 \\
\hline Former smoker & 221 \\
\hline Nonsmoker & 363 \\
\hline Smoker, unknown current status & 1 \\
\hline Unknown & 13 \\
\hline \multicolumn{2}{|c|}{ American Society of Anesthesiologists status } \\
\hline I & 15 \\
\hline$\|$ & 354 \\
\hline III & 344 \\
\hline IV & 10 \\
\hline \multicolumn{2}{|l|}{ No. of levels } \\
\hline 1 & 177 \\
\hline 2 & 294 \\
\hline 3 & 208 \\
\hline 4 & 47 \\
\hline Mean estimated blood loss, ml & 130.49 \\
\hline Mean op time, mins & 100.85 \\
\hline Mean length of stay, days & 1.81 \\
\hline \multicolumn{2}{|l|}{ Discharge disposition } \\
\hline Routine to home & 641 \\
\hline Home w/ home health care & 34 \\
\hline Postacute nonacute care setting & 39 \\
\hline Transfer to acute care & 9 \\
\hline Discharged, disposition unknown & 3 \\
\hline
\end{tabular}

* Values are given as the number of patients unless specified otherwise.

\section{Discussion}

The results of the current study suggest that a high level of preoperative back pain (>5 of 10) should not be a contraindication to decompression-only surgery in patients who otherwise are candidates for surgical decompression of symptomatic lumbar stenosis. Although the LP-Dominant patients ultimately had better 1-year postoperative scores, even the BP-Dominant patients had clinically significant improvements in all outcome measures, including back pain. While these findings are somewhat at odds with the frequent proposition that preoperative back pain is a poor prognostic factor and/or contraindication to decompression-only surgery, the data suggest the need for reconsideration of our existing assumptions.

In 2009, Kleinstück et al. reported on 221 patients from the European Spine Tango registry. ${ }^{10}$ The authors concluded that greater back pain relative to leg pain at baseline was associated with significantly worse outcome at 1 year after decompression surgery. Despite showing a medium
TABLE 2. Mean patient-reported outcome scores for the entire cohort $(n=726)$

\begin{tabular}{ccc}
\hline Variable & Score & p Value \\
\hline Back pain & & \\
\hline Baseline score & 7.62 & \\
\hline 3-mo score & 3.19 & 0.000 \\
\hline 12-mo score & 3.66 & 0.002 \\
\hline Leg pain & & \\
\hline Baseline & 7.23 & \\
\hline 3-mo score & 2.85 & 0.000 \\
\hline 12-mo score & 3.07 & 0.371 \\
\hline EQ-5D & & \\
\hline Baseline score & 0.55 & 0.000 \\
\hline 3-mo score & 0.76 & 0.613 \\
\hline 12-mo score & 0.75 & \\
\hline ODI & & 0.000 \\
\hline Baseline score & 49.11 & 0.030 \\
\hline 3-mo score & 27.20 &
\end{tabular}

effect size with multiple logistic regression analysis, the dichotomous analysis showed that patients with a "good" global outcome had preoperative back pain intensity of $4.3 \pm 3.1$ versus $5.3 \pm 2.9$ in the "poor" global outcome group. Additionally, $62 \%$ of patients who reported back pain as their major preoperative symptom had a "good" global outcome versus $80 \%$ of the patients who reported leg pain as their major preoperative symptom. ${ }^{10}$ Although the study supports the conventional wisdom (i.e., on average, patients with less preoperative back pain do "better" following decompression surgery), it is not clear that patients with significant preoperative back pain should be denied decompression-only surgery as the majority of patients had a "good" outcome and the overlap of preoperative back pain between the "good" and "poor" groups was substantial.

In 2015, Röder et al..$^{19}$ reported 50 matched pairs of patients from the SWISSspine registry (decompression plus interspinous process device) versus the Spine Tango registry (decompression-only controls) with preoperative back pain $\geq 5$ of 10 . At 7 to 9 months of follow-up, the interspinous process device group had greater improvement in back pain (3.8 vs 2.5 ) and leg pain (4.3 vs 2.5 ). In the decompression-only group, $60 \%$ of patients reported significant improvement in back pain. ${ }^{20}$ The major limitation of the study was comparing groups from 2 different registries. In the current study, back pain improvement ( 7.6 to 3.7) more closely matched the improvements seen in the group with an interspinous process device.

The strengths of the current study include the large number of patients from a prospective, multicenter database, which makes the findings generalizable. The limitations include the lack of granular data regarding the radiographic specifics of the spinal pathology. Data regarding spinal stability, alignment, and characterization of stenosis were not available. As per the $\mathrm{N}^{2} \mathrm{QOD}$ methodology, 
TABLE 3. Patient-reported outcome changes from baseline by the number of surgical levels

\begin{tabular}{|c|c|c|c|c|c|}
\hline \multirow[b]{2}{*}{ Variable } & \multicolumn{4}{|c|}{ Laminectomy Levels } & \multirow{2}{*}{$\begin{array}{c}\mathrm{p} \\
\text { Value }\end{array}$} \\
\hline & 1 & 2 & 3 & 4 & \\
\hline \multicolumn{6}{|l|}{ Back pain } \\
\hline Preop baseline score & 7.56 & 7.57 & 7.75 & 7.57 & 0.599 \\
\hline $\begin{array}{l}\text { 3-mo change in score } \\
\text { from baseline }\end{array}$ & 4.26 & 4.42 & 4.68 & 4.17 & 0.566 \\
\hline $\begin{array}{l}\text { 12-mo change in score } \\
\text { from baseline }\end{array}$ & 3.73 & 3.97 & 4.31 & 3.17 & 0.087 \\
\hline \multicolumn{6}{|l|}{ Leg pain } \\
\hline Preop baseline score & 7.18 & 7.20 & 7.54 & 6.15 & 0.004 \\
\hline $\begin{array}{l}\text { 3-mo change in score } \\
\text { from baseline }\end{array}$ & 4.22 & 4.24 & 4.61 & 4.12 & 0.692 \\
\hline $\begin{array}{l}\text { 12-mo change in score } \\
\text { from baseline }\end{array}$ & 3.86 & 4.07 & 4.73 & 3.30 & 0.032 \\
\hline \multicolumn{6}{|l|}{$E Q-5 D$} \\
\hline Preop baseline score & 0.55 & 0.54 & 0.56 & 0.58 & 0.666 \\
\hline $\begin{array}{l}\text { 3-mo change in score } \\
\text { from baseline }\end{array}$ & 0.19 & 0.20 & 0.21 & 0.16 & 0.902 \\
\hline $\begin{array}{l}\text { 12-mo change in score } \\
\text { from baseline }\end{array}$ & 0.19 & 0.20 & 0.21 & 0.16 & 0.512 \\
\hline \multicolumn{6}{|l|}{ ODI } \\
\hline Preop baseline score & 50.26 & 49.12 & 49.26 & 44.09 & 0.105 \\
\hline $\begin{array}{l}\text { 3-mo change in score } \\
\text { from baseline }\end{array}$ & 22.18 & 22.04 & 21.62 & 19.41 & 0.856 \\
\hline $\begin{array}{l}\text { 12-mo change in score } \\
\text { from baseline }\end{array}$ & 22.89 & 22.39 & 24.29 & 17.42 & 0.193 \\
\hline
\end{tabular}

the treating surgeon identified the primary diagnosis as lumbar stenosis, but neurogenic claudication versus radiculopathy was not stratified. The treating surgeon made the determination to proceed with decompression-only surgery, and therefore it may be assumed that no clear indication for stabilization or fusion was identified preoperatively. No patient in this series was reported to have spondylolisthesis or scoliosis. Likewise, specifics regarding surgical technique (e.g., laminotomy vs laminectomy, unilateral vs bilateral, tubular retractor vs midline) were not available. Although the previous literature does not support a clear difference in outcome based on the type of decompression, ${ }^{16}$ these are potentially relevant variables.

Another limitation is the lack of longer term followup. In the current study, the average back pain did slightly increase from the 3-month follow-up to the 12-month follow-up. The durability of the improvements beyond 1 year will require longer follow-up. Although prior studies do support the durability of lumbar stenosis surgery over many years, ${ }^{1,11}$ the durability of the improvements beyond 1 year requires longer follow-up. Certain patients may develop postdecompression instability and/or progressive degeneration of the decompressed segment(s). Data regarding potential revision surgeries in this cohort were not available. It is conceivable that concomitant stabilization would "protect" the operated segments and lead to better long-term outcomes. Of course, the theoretical risks
TABLE 4. Patient demographics and patient-reported outcomes by dominant symptom*

\begin{tabular}{|c|c|c|c|c|}
\hline Variable & $\begin{array}{c}\text { BP- } \\
\text { Dominant }\end{array}$ & $\begin{array}{l}\text { LP- } \\
\text { Dominant }\end{array}$ & $B P=L P$ & $\begin{array}{c}p \\
\text { Value }\end{array}$ \\
\hline No. of patients & 154 & 232 & 340 & \\
\hline Age, yrs & 65.16 & 67.18 & 64.79 & 0.063 \\
\hline Male sex & 94 & 121 & 192 & 0.222 \\
\hline Mean BMI, kg/m² & 30.56 & 29.21 & 30.69 & 0.028 \\
\hline Smoking status & & & & 0.455 \\
\hline Current every day smoker & 24 & 31 & 62 & \\
\hline $\begin{array}{l}\text { Current some days } \\
\text { smoker }\end{array}$ & 1 & 3 & 7 & \\
\hline Former smoker & 50 & 76 & 95 & \\
\hline Nonsmoker & 76 & 119 & 168 & \\
\hline $\begin{array}{l}\text { Smoker, unknown current } \\
\text { status }\end{array}$ & 1 & 0 & 0 & \\
\hline Unknown & 2 & 3 & 8 & \\
\hline $\begin{array}{l}\text { American Society of Anes- } \\
\text { thesiologists status }\end{array}$ & & & & 0.710 \\
\hline 1 & 4 & 5 & 6 & \\
\hline II & 74 & 123 & 157 & \\
\hline III & 73 & 101 & 170 & \\
\hline IV & 2 & 2 & 6 & \\
\hline No. of levels & & & & 0.003 \\
\hline 1 & 47 & 64 & 66 & \\
\hline 2 & 60 & 84 & 150 & \\
\hline 3 & 32 & 76 & 100 & \\
\hline 4 & 15 & 8 & 24 & \\
\hline $\begin{array}{l}\text { Mean estimated blood loss, } \\
\mathrm{ml}\end{array}$ & 117.15 & 120.62 & 143.90 & 0.349 \\
\hline Mean op time (mins) & 99.83 & 98.05 & 103.24 & 0.446 \\
\hline Mean length of stay (days) & 1.97 & 1.73 & 1.79 & 0.452 \\
\hline Discharge disposition & & & & 0.311 \\
\hline Routine to home & 142 & 201 & 298 & \\
\hline Home w/ home health care & 3 & 10 & 21 & \\
\hline $\begin{array}{l}\text { Postacute nonacute care } \\
\text { setting }\end{array}$ & 7 & 14 & 18 & \\
\hline Transfer to acute care & 1 & 5 & 3 & \\
\hline $\begin{array}{l}\text { Discharged, disposition } \\
\text { unknown }\end{array}$ & 0 & 1 & 0 & \\
\hline \multicolumn{5}{|l|}{ Back pain } \\
\hline Baseline score & 7.67 & 7.27 & 7.84 & 0.000 \\
\hline 3-mo score & 3.48 & 2.73 & 3.36 & 0.020 \\
\hline 12-mo score & 3.92 & $2.96 \dagger$ & 4.03 & 0.000 \\
\hline \multicolumn{5}{|l|}{ Leg pain } \\
\hline Baseline score & 5.80 & 7.61 & 7.61 & 0.000 \\
\hline 3-mo score & 2.64 & 2.73 & 3.02 & 0.429 \\
\hline 12-mo score & 2.92 & 2.72 & 3.37 & 0.056 \\
\hline \multicolumn{5}{|l|}{$E Q-5 D$} \\
\hline Baseline score & 0.55 & 0.56 & 0.55 & 0.757 \\
\hline 3-mo score & 0.72 & 0.79 & 0.77 & 0.043 \\
\hline 12-mo score & 0.75 & $0.80 \dagger$ & 0.72 & 0.000 \\
\hline
\end{tabular}

CONTINUED ON PAGE $600 »$ 
» CONTINUED FROM PAGE 599

TABLE 4. Patient demographics and patient-reported outcomes by dominant symptom*

\begin{tabular}{lcccc}
\hline \multicolumn{1}{c}{ Variable } & $\begin{array}{c}\text { BP- } \\
\text { Dominant }\end{array}$ & $\begin{array}{c}\text { LP- } \\
\text { Dominant }\end{array}$ & $\begin{array}{c}\text { BP = LP } \\
\text { Value }\end{array}$ \\
\hline ODI & & & & \\
\hline Baseline score & 48.11 & 49.15 & 49.54 & 0.627 \\
\hline 3-mo score & 27.51 & 24.81 & 28.64 & 0.088 \\
\hline 12-mo score & 27.25 & $21.29 \dagger$ & 29.46 & 0.000 \\
\hline $\begin{array}{l}\text { BMl = body mass index. } \\
*\end{array}$ & & & & \\
$+\begin{array}{l}\text { Value are given as the number of patients unless specified otherwise. } \\
\text { ent from the BP-Dominant and BP }=\text { LP cohorts. }\end{array}$
\end{tabular}

of nonunion, loss of fixation, and adjacent-segment degeneration would need to be less than the risk of progressive "same segment" deterioration for the benefits of stabilization to be realized.

The addition of fusion or stabilization to the initial decompression surgery may ultimately benefit a certain group of patients with lumbar stenosis. The current study cannot determine if the addition of fusion would have led to a greater improvement in the outcome scores for specific patients in the series. It is likely that certain lumbar stenosis patients from the participating centers met the surgeon's criteria for fusion and therefore were not included in the current series of decompression-only patients. Patients who required destabilizing facet resection and/ or spinal realignment to decompress stenosis may have been indicated for fusion and therefore would not be included in this series. Additionally, the residual leg pain in the patients in the current study may have been improved by more aggressive decompression that is facilitated by concomitant fusion.

The large number of patients with significant back pain who underwent decompression only at these centers suggests that preoperative back pain was not a primary indication for fusion or stabilization. One possible explanation is that the surgeon was able to differentiate between the type of "back pain" that may be due to muscle spasm or nerve irritation that the surgeon expected to get better with decompression only and the type of "back pain" for which the surgeon would typically recommend stabilization or fusion or nonsurgical management. The concept of relieving back pain by relieving stenosis may explain the greater improvement in back pain in the LP-Dominant group. Likewise, it is possible that certain patients with unrecognized preoperative instability or postdecompression instability were lost to follow-up and/or underwent revision surgery.

Measuring outcomes in spine surgery is undoubtedly complex. Outcomes research has evolved from surgeon assessments to patient-reported outcomes that introduce potential errors and biases such as response shift. Postoperative patients, now relieved of their stenosis symptoms, may place a different "value" on their "back pain" even though no true difference exists. It is also somewhat difficult to predict how an individual patient will categorize
TABLE 5. Number of patients who achieved MCID stratified by dominant symptom*

\begin{tabular}{|c|c|c|c|c|}
\hline \multirow[b]{2}{*}{ Variable } & \multicolumn{3}{|c|}{ No. of Patients (\%) } & \multirow[b]{2}{*}{$\begin{array}{c}\mathrm{p} \\
\text { Value }\end{array}$} \\
\hline & $\begin{array}{c}\text { BP- } \\
\text { Dominant }\end{array}$ & $\begin{array}{c}\text { LP- } \\
\text { Dominant }\end{array}$ & $\begin{array}{l}\text { BP Equal } \\
\text { to LP }\end{array}$ & \\
\hline $\begin{array}{c}\text { 12-mo back pain score } \\
\text { change }>1.2 \mathrm{MCID}\end{array}$ & $580(79.9)$ & $623(85.8)$ & $613(84.4)$ & 0.284 \\
\hline $\begin{array}{r}\text { 12-mo leg pain score } \\
\text { change }>1.6 \mathrm{MCID}\end{array}$ & $433(59.7) \dagger$ & $595(81.9)$ & $521(71.8)$ & 0.000 \\
\hline $\begin{array}{l}\text { 12-mo ODI score } \\
\text { change }>12.8 \mathrm{MCID}\end{array}$ & $486(66.9)$ & $547(75.4)$ & $463(63.8)$ & 0.013 \\
\hline
\end{tabular}

"buttock pain" (i.e., some patients may consider pain in the buttock area to be "leg pain" while others may consider it to be "back pain").

Despite the acknowledged limitations, the strength of the current registry study is identifying knowledge gaps based on current "real-world" patient data using current "state of the art" patient-reported outcomes. The current study sheds significant light on the 1-to-10 numeric rating score for "back pain" that is widely used in the current spine literature, and thereby may help further the understanding of patient-reported outcomes following spine surgery.

\section{Conclusions}

The current study shows that "back pain" relief can be obtained with decompression-only surgery in appropriately selected patients with symptomatic stenosis. Future studies are needed to identify the specific preoperative factors that predict the failure of decompression-only surgery and thereby justify the increased complexity and cost of fusion or stabilization during the surgical decompression of lumbar spinal stenosis in the absence of significant spondylolisthesis or scoliosis.

\section{References}

1. Amundsen T, Weber H, Nordal HJ, Magnaes B, Abdelnoor M, Lilleâs F: Lumbar spinal stenosis: conservative or surgical management?: A prospective 10-year study. Spine (Phila Pa 1976) 25:1424-1436, 2000

2. Asher AL, Speroff T, Dittus RS, Parker SL, Davies JM, Selden N, et al: The National Neurosurgery Quality and Outcomes Database (N2QOD): a collaborative North American outcomes registry to advance value-based spine care. Spine (Phila Pa 1976) 39 (22 Suppl 1):S106-S116, 2014

3. Chou R, Baisden J, Carragee EJ, Resnick DK, Shaffer WO, Loeser JD: Surgery for low back pain: a review of the evidence for an American Pain Society Clinical Practice Guideline. Spine (Phila Pa 1976) 34:1094-1109, 2009

4. Copay AG, Glassman SD, Subach BR, Berven S, Schuler TC, Carreon LY: Minimum clinically important difference in lumbar spine surgery patients: a choice of methods using the Oswestry Disability Index, Medical Outcomes Study questionnaire Short Form 36, and pain scales. Spine J 8:968-974, 2008

5. Davis RJ, Bae HW, Errico TJ, Lauryssen C, Leary SP: 
Decompression and implantation of an interlaminar stabilization implant for the treatment of lumbar spinal stenosis with back pain: four year outcomes from a Level 1 US IDE study. Presented at the International Society for Advancement of Spine Surgery 15th Annual Meeting, San Diego, CA, 2015 (Abstract) (http://www.paradigmspine.com/ sites/default/files/ISASS\%20Abstract_coflex\%C2\%AE\%20 4-Year\%20Data\%20Abstract.pdf) [Accessed April 7, 2016]

6. Davis RJ, Errico TJ, Bae H, Auerbach JD: Decompression and Coflex interlaminar stabilization compared with decompression and instrumented spinal fusion for spinal stenosis and low-grade degenerative spondylolisthesis: two-year results from the prospective, randomized, multicenter, Food and Drug Administration Investigational Device Exemption trial. Spine (Phila Pa 1976) 38:1529-1539, 2013

7. EuroQol Group: EuroQol-a new facility for the measurement of health-related quality of life. Health Policy 16:199208, 1990

8. Fairbank JC, Pynsent PB: The Oswestry Disability Index. Spine (Phila Pa 1976) 25:2940-2952, 2000

9. Golinvaux NS, Bohl DD, Basques BA, Fu MC, Gardner EC, Grauer JN: Limitations of administrative databases in spine research: a study in obesity. Spine J 14:2923-2928, 2014

10. Kleinstück FS, Grob D, Lattig F, Bartanusz V, Porchet F, Jeszenszky D, et al: The influence of preoperative back pain on the outcome of lumbar decompression surgery. Spine (Phila Pa 1976) 34:1198-1203, 2009

11. Lee JY, Whang PG, Lee JY, Phillips FM, Patel AA: Lumbar spinal stenosis. Instr Course Lect 62:383-396, 2013

12. Malmivaara A, Slätis P, Heliövaara M, Sainio P, Kinnunen $\mathrm{H}$, Kankare J, et al: Surgical or nonoperative treatment for lumbar spinal stenosis? A randomized controlled trial. Spine (Phila Pa 1976) 32:1-8, 2007

13. McGirt MJ, Parker SL, Asher AL, Norvell D, Sherry N, Devin CJ: Role of prospective registries in defining the value and effectiveness of spine care. Spine (Phila Pa 1976) 39 (22 Suppl 1):S117-S128, 2014

14. McGirt MJ, Speroff T, Dittus RS, Harrell FE Jr, Asher AL: The National Neurosurgery Quality and Outcomes Database $\left(\mathrm{N}^{2} \mathrm{QOD}\right)$ : general overview and pilot-year project description. Neurosurg Focus 34(1):E6, 2013

15. Omidi-Kashani F, Hasankhani EG, Ashjazadeh A: Lumbar spinal stenosis: who should be fused? An updated review. Asian Spine J 8:521-530, 2014

16. Overdevest GM, Jacobs W, Vleggeert-Lankamp C, Thomé C, Gunzburg R, Peul W: Effectiveness of posterior decompression techniques compared with conventional laminectomy for lumbar stenosis. Cochrane Database Syst Rev 3:CD010036, 2015

17. Phillips FM, Slosar PJ, House JA, Andersson G, Papatheofanis F: Lumbar spine fusion for chronic low back pain due to degenerative disc disease: a systematic review. Spine (Phila Pa 1976) 38:E409-E422, 2013

18. Resnick DK, Watters WC III, Mummaneni PV, Dailey AT, Choudhri TF, Eck JC, et al: Guideline update for the performance of fusion procedures for degenerative disease of the lumbar spine. Part 10: lumbar fusion for stenosis without spondylolisthesis. J Neurosurg Spine 21:62-66, 2014

19. Röder C, Baumgärtner B, Berlemann U, Aghayev E: Superior outcomes of decompression with an interlaminar dynamic device versus decompression alone in patients with lumbar spinal stenosis and back pain: a cross registry study. Eur Spine J 24:2228-2235, 2015

20. Sarrazin MS, Rosenthal GE: Finding pure and simple truths with administrative data. JAMA 307:1433-1435, 2012

21. Weinstein JN, Tosteson TD, Lurie JD, Tosteson AN, Blood E, Hanscom B, et al: Surgical versus nonsurgical therapy for lumbar spinal stenosis. N Engl J Med 358:794-810, 2008

\section{Disclosures}

Dr. Crawford is a consultant for Alphatec and Medtronic and receives honoraria from Titan Spine. Dr. Glassman is a consultant for and receives royalties from Medtronic, and he is on the board of directors of the Scoliosis Research Society. Dr. Knightly is on the board of directors of the NeuroPoint Alliance. Dr. Mummaneni is a consultant for and receives royalties from DePuy Synthes Spine, owns stock in Spinicity/ISD, receives grants from AOSpine, and receives royalties from Taylor and Francis Publishing, Springer Publishing, and Thieme Publishing.

\section{Author Contributions}

Conception and design: Crawford, Glassman. Acquisition of data: all authors. Drafting the article: Crawford. Critically revising the article: all authors. Reviewed submitted version of manuscript: all authors.

\section{Correspondence}

Charles H. Crawford III, Norton Leatherman Spine Center, 210 East Gray St., Ste. 900, Louisville, KY 40202. email: chcraw01@ gmail.com. 